ISSN: 0186-0348, ISSN electrónico: 2395-8464

DOI: http://dx.doi.org/10.18234/secuencia.v0i57.824

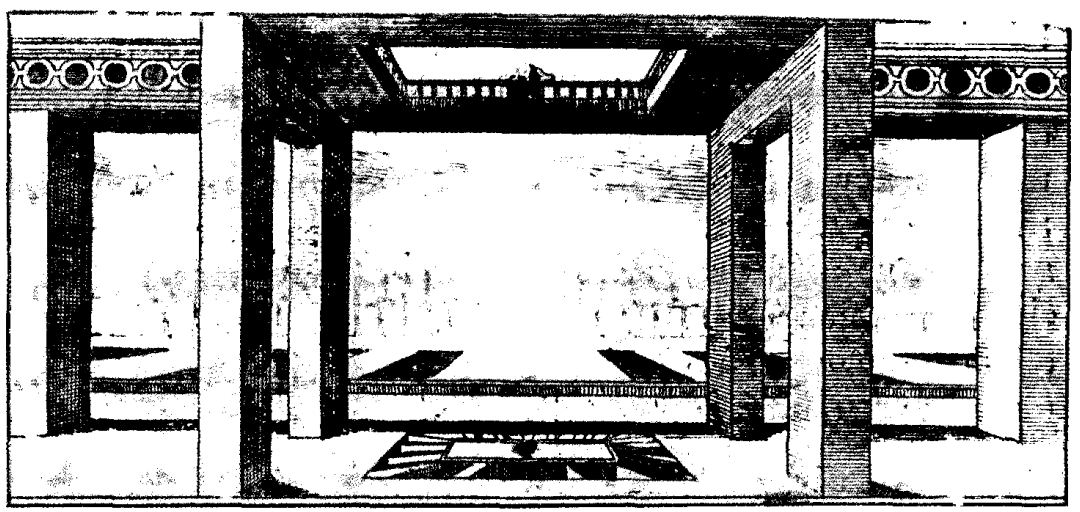




\section{Manuel Cbust Calero / Ivana Frasquet}

Manuel Chust Calero cursó sus estudios de licenciatura y doctorado en la Universidad de Valencia, donde recibió el Premio Extraordinario de Doctorado en 1993. Profesor titular de Historia de América Latina en la Universidad Jaume I de Castellón, España. Fue director del Departamento de Historia y actualmente es vicerrector de la misma universidad. Especialista en la primera mitad del siglo XIX en España y México, ha publicado numerosos estudios acerca de diversos aspectos de los procesos revolucionarios liberales en España y México, en especial sobre constitucionalismo y parlamentarismo, federalismo y fuerzas armadas. Destaca, entre sus numerosas publicaciones, La cuestión americana en las Cortes de Cádiz. Ha realizado estancias de investigación y docencia, entre otras, en la UNAM, Instituto Mora, Colegio de Michoacán, Universidad Veracruzana, Universidad de Buenos Aires, Universidad de Toulouse y Universidad Pablo de Olavide de Sevilla.

Ivana Frasquet es investigadora del Departamento de Historia, Geografía y Arte de la Universitat Jaume I de Castellón. Miembro del Centro de Investigaciones de América Latina de la misma universidad. Su tesis de licenciatura, "Sociabilidad, cultura y ocio en la Valencia revolucionaria. 1834-1843", defendida en la Universitat Jaume I de Castellón obtuvo el Premio Senyera de Investigaciones Históricas del Ayuntamiento de Valencia en el año 1999. Ha realizado estancias de investigación en México, en la Universidad Veracruzana y en la Universidad Autónoma de Puebla. Entre sus publicaciones se encuentran: Valencia en la revolución. 1834-1843, Sociabilidad, cultura y ocio, así como diversos artículos sobre la construcción del Estado-nación en México en Relaciones, Mexican Studies/Estudios Mexicanos, Tiempos de América, etc. Actualmente trabaja su tesis doctoral sobre la trascendencia de las Cortes de Cádiz en México.

\section{Resumen}

Desde el primer día de sus sesiones, las Cortes de Cádiz tuvieron un objetivo principal, consustancial a cualquier revolución liberal: la elaboración de una Constitución liberal. La composición singular de las Cortes se debía a la reunión de representantes de "todos los territorios de la monarquía", lo cual provocó que las propuestas revolucionarias liberales se conjugaran con los diversos intereses territoriales que representaban las realidades americana y peninsular. Esta problemática se evidenció, notoriamente, en la discusión parlamentaria de los tres primeros y trascendentales artículos constitucionales, que establecieron las bases teóricas y conceptuales del nuevo Estado-nación hispano, objeto de estudio de este artículo.

Palabras clave:

Cortes de Cádiz, Constitución de 1812, liberalismo, monarquía, soberanía, nación, pueblo.

\section{Abstract}

From the first day of their sessions, on September 24 1810, the Courts of Cadiz had one main objective, inseparable from any liberal revolution: the drawing up of a liberal Constitution. The composition of the courts was unusual in that it included representatives from "all the territories in the monarchy", meaning that liberal, revolutionary proposals combined with the various territorial interests that represented American and peninsular realities. This problem was particularly evident in the parliamentary discussion of the crucial first three articles of the Constitution establishing the theoretical and conceptual bases of the new Spanish nationstates, which will be analyzed in this article.

Key words:

Courts of Cadiz, Constitution of 1812, liberalism, monarchy, sovereignty, nation, people.

Fecha de recepción: octubre de 2002

Fecha de aceptación: enero de 2003 


\title{
Soberanía, nación y pueblo en la Constitución de 1812
}

\author{
Manuel Cbust Calero \\ Ivana Frasquet
}

PRIMER ACTO

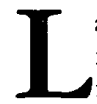

as Cortes generales y extraordinarias comienzan sus sesiones en el teatro de la isla de León. Su nomenclatura no es gratuita: se ha convocado a todos los territorios de la monarquía -"generales"-, y tanto la convocatoria como el momento ciertamente son "extraordinarios". Habrá que seguir poniendo especial énfasis en este hecho sin precedentes en la historia universal contemporánea. Sobre todo por su trascendencia en, al menos, la primera mitad del siglo para una pluralidad de repúblicas americanas y, cómo no, para el Estado español.

Transcurridas unas pocas horas, un diputado por Extremadura se dirigió a la Cámara glosando

cuán conveniente sería decretar que las Cortes generales y extraordinarias estaban legítimamente instaladas: que en ellas residía la soberanía, que convenía dividir los tres poderes, legislativo, ejecutivo y judicial [...] y que se renovase el reconocimiento del legítimo rey de España, el señor don Fernando VII, como primer acto de soberanía de las Cortes.

Diego Muñoz Torrero se dio a conocer en la Cámara. Su condición de eclesiásti- co no pareció importunarlo para tamañas propuestas. No estaba solo en sus peticiones, lo acompañaba la fracción más granada del liberalismo. Las Cortes, en minutos, accedieron a sus pretensiones.

Pero no fue Muñoz Torrero quien tomó la palabra, de inmediato Manuel Luján, también diputado por Extremadura, presentaba al secretario de la Cámara para su lectura un pliego redactado que recogía en once puntos la iniciativa de Muñoz Torrero. La táctica estaba perfectamente estudiada. ¿Alguien cuestiona el funcionamiento de "partidos" -en cuanto a partidarios de unas mismas ideas? Éste y una pluralidad de hechos lo desmienten. Otra cosa será si se tiene una concepción presentista y politóloga del término.

Digámoslo. Resaltémoslo. Se trataba de una de las cuestiones más importantes de las Cortes: ¡la soberanía nacional! El primer punto declaraba "hallarse los diputados que componen este Congreso, y que representan la nación, legítimamente constituidos en Cortes generales y extraordinarias, en quienes reside la soberanía nacional". Legitimados por una soberanía que no la otorgaba el rey... sino la nación. ¡Atrevidos estos diputados! Quizá más bien ¡revolucionarios! En todo el sentido pleno del término. ¿No se reunían las Cortes para reformar las leyes funda- 
mentales? ¿No era éste el tono recurrente de los discursos y parabienes tanto de los diputados liberales como de los "serviles"? ¿E, incluso, de la mayor parte de la Cámara que no estaba alineada con uno y otro sector, los eclécricos?

En el segundo punto, las Cortes reconocían como rey a Fernando VII, al tiempo que declaraban nula la cesión de la corona en favor de Napoleón. Insistamos: era la soberanía de la nación quien reconocía al rey y no al contrario. ¿Hablamos de revolución? Sí.

El tercero establecía la división de poderes. ${ }^{1}$ Es más, el sexto punto ordenaba que el Consejo de Regencia acudiera a la sala de reuniones de las Cortes para reconocer que la soberanía nacional residía en las Cortes. Obsérvese: el ejecutivo y el rey se subordinaban al legislativo. Cortes, legislativo, que asumirán durante toda la situación revolucionaria de 1810 a 1814 tareas propias del ejecutivo.

Cuatro de los cinco regentes, ya pasada la media noche, lo hicieron. La excepción la constituyó el obispo de Orense, excusándose en lo avanzado de su edad y "en la entrada de la noche". Como es conocido, no sólo no acatará el decreto, sino que también se negará a jurar fidelidad a las Cortes. Por último, el punto onceavo establecía la inviolabilidad de los diputados. La Inquisición, vigente hasta su abolición por las Cortes en 1813, estaba más que presente en las cabezas de los diputados liberales.

Representación, legitimidad, soberanía, nación y soberanía nacional... cuestiones, problemas, conceptos y consignas del

\footnotetext{
${ }^{1}$ Véase Barragán, Temas, 1978. En especial el segundo capítulo.
}

liberalismo, tanto a niveles teóricos como políticos. Pero ahora se estaba en revolución, en unas Cortes revolucionarias y también en una doble guerra revolucionaria, en América y en la península. La singularidad de la revolución hispana trascendía los paradigmas liberales. Insistamos. La convocatoria de representación nacional por el decreto de febrero de 1810 se había extendido a todos los territorios de la monarquía española, esto es, también a América y a las posesiones asiáticas. ¿Quería decir esto que la nación comprendía a todas las provincias de la monarquía española? Parecía evidente. Pero advirtamos, el concepto nación se definía no sólo en cuanto a entidad cultural, sino también desde una concepción políticoadministrativa y de territorio al unirlo con el de provincia.

Nación: población y territorio. Aún quedaba casi un año para el debate de su definición constitucional, pero ésta y la problemática que suscitará ya estaban planteadas desde el primer día de las Cortes. Una nación concebida, propuesta, en términos hispanos. No lo olvidemos.

Es más, en la teoría filosófica que trasladaban los liberales a las Cortes, era la nación quien reclamaba desde principios historicistas, iusnaturalistas, contractuales - escolásticos suarecianos la asunción de la soberanía por el "pueblo", dado que el monarca estaba "secuestrado" y, por lo tanto, "ausente". Si la soberanía volvía a la nación, la representación de ésta recaía en las Cortes. Aconteció que éstas también habían experimentado un cambio en la forma de representación, ya que ahora era en los diputados donde residía la representación de la totalidad de esa nación, siguiendo el principio de representación y soberanía más clásico.

Manuel Chust Calero / Ivana Frasquet 
La propuesta, revolucionaria, de Diego Muñoz Torrero y Manuel Luján se completó al día siguiente. Una vez aprobada la división de poderes intervino otro liberal, José Mejía Lequerica. ${ }^{2}$ Éste, diputado suplente por Santa Fe de Bogotá, propuso a la Cámara la aprobación de una nomenclatura unitaria para los tratamientos protocolarios que debían tener los tres poderes. Planteó que al poder ejecutivo $\mathrm{y}$ al poder judicial se los denominara alteza, y al poder legislativo, es decir, a las Cortes, majestad. Era, sin declararlo, la asunción de uno de los principios básicos del liberalismo: la división de poderes. Hasta aquí nada nuevo en el universo de las revoluciones liberales, léase la inglesa, la estadunidense y la francesa. La propuesta además llevaba aparejada, observémoslo, una clara intención de dotar a esta conquista liberal de legitimidad: majestad, reservada al colectivo de representantes de la nación. Tenemos el conflicto entre legislativo y monarquía planteado por un diputado liberal... jamericano! también... ¿español? ¿Pesaba su condición ultramarina o su praxis política? De esta propuesta se deduce lo segundo, de momento. ¿O quizá la separación de su condición nacional y política sea una mera cuestión historiográfica?

La propuesta de Mejía no era gratuita. En absoluto. Tratamientos de significación y origen monárquicos para los tres poderes. La línea legitimadora monárquica se aseguraba. Señas de identidad: la primera será la monarquía, la otra será la religión del "pueblo" español y americano en esta revolución, no lo olvidemos. Los ejemplos son múltiples.

\footnotetext{
${ }^{2}$ Chust, "Revolución", 2000, pp. 43-62.
}

Mejía justificaba, desde la supuesta necesidad del protocolo parlamentario, una legitimación de la que carecían las Cortes. Pero ino era en las Cortes donde residía la representación de la nación y en ellas estaba depositada la soberanía? ¿Por qué ahora el tratamiento de majestad? Había una importante problemática de legitimidad. Recordemos que en la monarquía absoluta, la única legitimidad del Estado, la soberanía, residía en el rey y no en un sistema representativo igualitario que además no contaba con una convocatoria expresa de real, sino con la de "nacional". Por ello, el astuto Mejía arrebató jurídicamente su estatus exclusivo al monarca y trasladó su legitimidad a los representantes que la nación había elegido por votación popular. Así, y a fuerza de la repetición, el tratamiento majestad resonó una y otra vez entre las paredes del teatro de la isla de León, en primer lugar, y después en la planta elíptica de San Felipe Neri. Majestad era el tratamiento enunciativo y de cortesía usual con el que todos los diputados empezaban sus discursos. Las Cortes usaron una táctica obvia, la repetición como forma de introducir la costumbre.

Además, el tratamiento de alteza lo trasladó también al poder judicial. Aquel que hasta ese mismo momento era señorial y privativo del rey y de la nobleza. La propuesta implicaba aún más cosas. Era un auténtico referente mental y legitimador para lo que los historiadores franceses gustan denominar, sin aclarar, "imaginario colectivo" e, incluso, últimamente "imaginario social". Nacía un nuevo poder deslindado del ejecutivo, con autonomía de éste y sin estar subordinado, pero falto de legitimación. Ausente de legitimidad divina, carente de referentes 
de soberanía, a no ser la que estaba construyendo el liberalismo hispano; éste recurrió a justificaciones escolásticas para solventar la nueva coyuntura revolucionaria imprevista desde 1808 .

Se formulaba así por los intelectuales orgánicos liberales el pacto traslatii suareciano: en "ausencia del monarca, la soberanía regresaba al pueblo". Desde la propuesta de Mejía, majestad era ahora la nación, jcompuesta por los representantes de ambos hemisferios! Pero ¿qué era la nación para el "imaginario colectivo"? ¿Quiénes debían ser y mediante qué requisitos sus representantes? Es más, ¿a quién representaban? Y sobre todo, ¿en función de qué argumentos, justificaciones y teoría? Todo un problema nacional se enunciaba desde el primer día de este parlamento hispano. Hábilmente los diputados liberales de ambas fracciones, la americana y la peninsular, manejaban mistificadoramente el concepto de nación con significados diferentes, en unas ocasiones se referían al Estado-nación y en otras tan sólo a la nación. Lo veremos más adelante.

\section{SEgUNDO ACTO}

Once meses después comenzó la discusión del proyecto de Constitución. Las Cortes estaban ya, desde enero, en el oratorio de San Felipe Neri.

El presidente de las Cortes, a la sazón Ramón Giraldo, convocó a los diputados, peninsulares y americanos, a los debates constitucionales, instando al público de las galerías a guardar silencio ante la magnitud de la obra que aquel día comenzaba. El proyecto de elaboración de la Constitución había sido encargado a una comisión formada por quince miembros entre los cuales diez eran peninsulares y cinco americanos. ${ }^{3}$ Es de resaltar esta composición, relevante en cuanto a la redacción última que tendrá la Carta Magna.

Comenzó el presidente con un emotivo discurso. La tesis de la reforma de la Constitución se mantuvo. A estas alturas de las Cortes muchos diputados sabían que era pura retórica. No tardó en ponerse de manifiesto. Ramón Giraldo:

Hoy se empieza a discutir el proyecto formado para el arreglo y mejora de la Constitución política de la nación española, y vamos a poner la primera piedra del magnífico edificio que ha de servir para salvar a nuestra afligida patria [...]

Empecemos pues la grande obra, para que el mundo entero y la postericlad vean siempre que estaba reservado sólo a los españoles mejorar y arreglar su Constitución, hallándose las Cortes en un rincón de la península, entre el estruendo de las armas enemigas, combatiendo con el mayor de los tiranos, cuya cerviz se humillará más con este paso que con la destrucción de sus ejércitos. ${ }^{4}$

El debate del proyecto constitucional comenzó con la lectura del preámbulo y el título I "De la nación española y de los españoles" y del capítulo I "De la nación española". Previamente al texto constitucional, la comisión convino en incluir

${ }^{3}$ Chusr, Cuestión, 1999. El tercer capítulo trata sobre el comienzo de las sesiones constitucionales, los diputados que intervienen en la comisión, sus lugares de procedencia y su ideología.

${ }^{4}$ Diario de Sesiones de Cortes, 25 de agosto de 1811 (en adelante, $D S C$ ). 
una invocación. ¿Volvían los problemas de legitimidad? La soberanía residía en la nación, pero la propuesta de Estado que los liberales formulaban seguía teniendo un problema de legitimidad. El recurso a la religión como ente legitimador se hizo imprescindible, al igual que la cobertura monárquica, si bien su titular, y quizá por eso mismo, estaba "ausente" y "traicionado". No era una concesión liberal, como hasta ahora se ha planteado, era una necesidad del liberalismo hispano. Al igual que pasará con el artículo 12 de la Constitución.

En el nombre de Dios Todopoderoso, Padre, Hijo y Espíritu Santo, autor y supremo legislador de la sociedad.

Las Cortes generales y extraordinarias de la nación española, bien convencidas, después del más detenido examen y madura deliberación, de que las antiguas leyes fundamentales de esta monarquía, acompañadas de las oportunas providencias y precauciones que aseguren de un modo notable y permanente su entero cumplimiento, podrán llenar debidamente el grande objeto de promover la gloria, prosperidad y el bienestar de toda la nación, decretan la siguiente Constitución política para el buen gobierno y recta administración del Estado. ${ }^{5}$

Dos problemáticas centrarán estos primeros momentos del debate constitucional. Varios diputados mostraron su sorpresa, a veces casi indignación, por el poco tiempo que habían tenido para leer el texto constitucional. Y no en su totalidad, pues la comisión de Constitución sólo había entregado un tercio del texto cuando

${ }^{5}$ Ibid. comenzó el debate de la misma. En este sentido intervinieron Jaime Creus, Miguel Riesco y Alonso Cañedo que expusieron, molestos, la premura con que la presidencia había señalado el inicio de la discusión del texto. La táctica de los diputados liberales que conformaban la comisión se vislumbraba ya en sus primeras intervenciones, también su connivencia con el presidente para precipitar la fecha de inicio del debate.

El escaso tiempo que se dio a los diputados para la lectura del texto es síntoma de la tapidez con que los liberales querían aprobar estos primeros artículos, dado su contenido fundamental. La fracción liberal sabía que el factor sorpresa y la necesidad de aprobar la Constitución de forma inmediata - no olvidemos que los franceses estaban asediando la ciudad y las discusiones se realizaban con el estruendo de los cañones de fondo, que la insurgencia en América proseguía y que las conspiraciones absolutistas no estaban controladas-, jugaban a su favor para conseguir sancionar un código liberal, incluso en algunos aspectos democráticos, que el sector servil nunca hubiera permitido. Es más, estos diputados se opondrán decididamente, como veremos. A ello hay que añadir el desconcierto de algunos diputados a la hora de debatir los artículos, pues la comisión iba entregando el proyecto por partes y en ocasiones se discutían puntos que requerían las intervenciones reiteradas de los miembros de la comisión para aclarar que se trataban en artículos posteriores. Será toda una constante a lo largo del debate constitucional. ¿Le faltó tiempo a la comisión para terminar todo el proyecto? ¿Lo entregó fraccionado como parte de una estrategia política? Las dos premisas parecen factibles. 
La intervención de Creus no terminó aquí. Sutilmente interrogó a las Cortes sobre si hubo o no unanimidad en la comisión de Constitución en la redacción final del proyecto. Sabía que José Pablo Valiente se había negado a firmarlo. Es más, demandaba a la comisión explicaciones sobre las razones que había tenido para ello. Efectivamente, Valiente, diputado por Sevilla y consejero de Indias, se negó a dar su consentimiento al proyecto presentado por la comisión. Muñoz Torrero intervino matizando la cuestión. Su oposición se refería a ciertos artículos, no a la totalidad. Salió a la tribuna Valiente. Fue claro. Explicó su negativa porque tampoco la comisión pudo examinar la totalidad del proyecto antes del inicio del debate, además de oponerse al contenido de determinados artículos que no especificó. Las razones liberales, la premura del tiempo: "V. M. y el público deseaban con ansia que esto se llevase a efecto." 6

De inmediato el sector liberal respondió. Evaristo Pérez de Castro, Joaquín Fernández de Leiva, Diego Muñoz Torrero y Alonso Cañedo intervinieron defendiendo lo difícil que resultaba que quince individuos estuvieran de acuerdo en todos los artículos, por lo que la tarea de la comisión era debatir las diferentes interpretaciones y redacción del texto propuesto. Insistían en que "el proyecto que se presenta es el resultado del acuerdo de la mayoría de la comision", ' y que los diputados podrían exponer sus votos en el lugar correspondiente. Como sabemos, la problemática de Valiente se interpreta desde su oposición como absolutista.

\footnotetext{
${ }^{6} \mathrm{Ibid}$.

${ }^{7}$ Ibid., p. 1684.
}

Pero volvamos a la discusión del preámbulo. El sector absolutista se lanza a la batalla dialéctica nada más por conocer el contenido del mismo. El objeto de la discusión, en primer lugar, la invocación religiosa de la escueta introducción que da paso al articulado. Los diputados absolutistas y también algún ecléctico, reclaman que se explicite mejor la profesión de fe de la nación, les parece escueta y demasiado concisa, por lo que exigen una exposición clara que enuncie que la religión es la católica. No están solos. Algún liberal, como Joaquín Lorenzo Villanueva, diputado valenciano, los acompaña. Éste también es eclesiástico. Algunos van más lejos y piden que se nombre a Jesucristo y a la Virgen, pues la invocación de la Santísima Trinidad es necesaria, pero incompleta, manifiesta Miguel Alfonso Villagómez. El obispo de Calahorra intervino:

Aquí se trata de una Constitución elemental para España: se trata de una nación católica, la primera en el mundo [...] Póngase: creo firmemente esto, lo otro y lo de más allá. Póngase que Dios es el autor de todas las cosas, de todo lo visible e invisible, y que nos redimió; y también se hará como se debe poniendo: creo todo lo que dice la Santa Iglesia católica, apostólica, romana. ${ }^{8}$

La nación católica... ${ }^{9}$ entramos en una de las problemáticas más sugestivas, al tiempo que difíciles de resolver, para los liberales. Los fundamentos teóricos del Estado liberal hispano partían desde una premisa incuestionable, la legitimidad

${ }^{8}$ Ibid.

${ }^{9}$ Véase Portillo, Revolución, 2000. 
que el liberalismo precisaba y no tenía. Eran dos: monarquía y catolicismo. Acontecía que ambos eran los fundamentos del Estado absoluto. Es más, signos de identidad de la nación española, en términos culturales. La mistificación, el historicismo practicado por muchos liberales, se volvía como una excusa recurrente. Con todo, proseguía la revolución. No era "beatería", ni "traición", ni oportunismo de los liberales como han señalado algunos autores, en especial los historiadores del derecho. ${ }^{10}$ Eran dos aspectos trascendentales y consustanciales con los signos de identidad del nacionalismo español emergente y revolucionario, pero aún no triunfante.

Hacer la revolución al tiempo que ganar la guerra recurriendo a premisas republicanas y laicas no era posible en la España y América del siglo XIX. Esto recordaba a la Francia jacobina, al Estado republicano, federal y protestante de Estados Unidos. Los liberales, muchos de ellos eclesiásticos, en unas Cortes cuyo recinto era una iglesia, lejos de tener ideas alejadas de la realidad analizaban correctamente ésta.

De nuevo es Fernández de Leiva, un diputado chileno, quien responde. Indica que la profesión de fe ya se trata en un artículo posterior, concretamente en el número $13 .{ }^{11} \mathrm{Y}$ prosigue. Leiva, firme, insistió en que en el preámbulo no era necesario extenderse más, puesto que correspondía a la nación reiterar dicha profesión y en la invocación inicial no era el momento para desarrollar esta idea. Su-

${ }^{10}$ Véase Varela Suances, Teoria, 1983; Stoetzer, Pensamiento, 1966.

${ }^{11}$ En la Constitución finalmente llevará el número 12 . bió a la tribuna Mariano Mendiola, diputado por Querétaro, para apoyarlo. Astuto, instó a la brevedad y sencillez que la obra debía tener, al igual que el Evangelio. También Antonio Oliveros intervino. Extremeño, liberal y eclesiástico, fue contundente. Consideraba innecesarias las adiciones que se proponían y creía que la invocación resumía perfectamente el espíritu de la comisión. La Constitución necesitaba una legitimación que no tenía, ésta sólo podía ser, de momento, divina y religiosa. Oliveros: "Se invoca a la Divinidad, como que es quien puede dar una sancion a las leyes que los hombres no pueden dar. Esto basta a mi juicio para satisfacer a las dudas propuestas." 1

No se dieron fácilmente por vencidos los absolutistas. Era otro su planteamiento. No era una legitimación lo que proponían, sino una confesionalidad del Estado, cosa que lograrán en el artículo 12. Había más. Los absolutistas pretendían además un reconocimiento divino de sus formas políticas. Aquí se estableció una de las fronteras entre liberales y absolutistas. Una cosa eran las inexcusables señas de identidad de la "nación española", otra transigir con la concepción teocrática del Estado.

Juan Lera, por parte de los serviles, prosiguió. Considerando que siendo la Constitución "un código breve" -con esta afirmación quedaba claro que la mayor parte de los diputados no sabían la totalidad de su extensión: ;384 artículos!necesario para la formación de los niños en la escuela, se debía extender más en la explicación de la religión. La propuesta de Lera era otra. La elaboración de un cate-

${ }^{12}$ DSC, 25 de agosto de 1811 , p. 1686. 
cismo político-religioso, que después va a proliferar, pero en un sentido liberal.

Una vez más Muñoz Torrero, ya cansado del asunto, argumentó que la educación de la religión correspondía al catecismo y no a la Constitución. Se unió también a la discusión José Espiga. Zanjó la cuestión: "La majestad de una Constitución consiste en decir bajo pocas palabras todo cuanto se puede desear."13

Era el turno de Agustín Argüelles. Lo peligroso de la situación lo requería. El debate no sólo amenazaba con prolongarse, sino con enmarañarse más de lo aconsejable. Comenzaban a salir cuestiones trascendentales y jaún se estaba en la invocación! Finalmente se aprobó el texto de la invocación tal y como lo presentó la comisión, a excepción del cambio de la frase bienestar de la nación por bien de la nación. No parecía un aspecto importante para los liberales.

\section{DE LA NACIÓN ESPAÑOLA...}

Sin perder el tiempo se leyó el artículo $1^{\circ}$, capítulo I del título I del proyecto presentado por la comisión:

TÍTULO I: DE LA NACIÓN ESPAÑOLA Y DE LOS ESPAÑOLES

CAPÍTULO I: De la nacion española

Artículo $1^{\circ}$ : La nacion española es la reunión de todos los españoles de ambos hemisferios. ${ }^{14}$

El primer diputado en intervenir fue Francisco Javier Borrull, del sector servil. Un diputado ciertamente interesante. Culto, formado, austracista y con propues-

\footnotetext{
13 lbid.

${ }^{14}$ Ibid., p. 1684.
}

tas foralistas. Calificó la redacción de demasiado general. Será toda una constante en este debate. Es importante su apreciación. Entendía como nación española al territorio peninsular, por lo que convenía en excluir a los portugueses. Por ello, su propuesta concretaba la idea de nación añadiendo al artículo la frase: "bajo de un mismo gobierno y nuestras leyes fundamentales". ${ }^{15}$ Borrull, docto, aludió a las partidas de Alfonso X el Sabio: "pueblo es el ayuntamiento de todos los hombres". ${ }^{16}$ ¿Provenía de aquí la base del texto constitucional? Era una de las primeras definiciones del concepto "pueblo". Como vemos, Borrull recurría a una definición consuetudinaria.

Convenía la aclaración. Evaristo Pérez de Castro, diputado por Valladolid y miembro de la comisión, advirtió que la aclaración de nacionalidad y territorio venía expresada en artículos posteriores. Una vez más, los problemas por el desconocimiento del texto constitucional al completo se evidenciaban. No fueron los únicos. La confusión Estado, nación, Estado-nación, se manifestó nítidamente. Los diputados se intercambiaban discursos con estos conceptos. Sabían que no estaban hablando de lo mismo. No importaba. Ésa era la estrategia tanto de liberales como de absolutistas. Especialmente de los primeros, sumidos en un discurso político historicista, en ocasiones, pragmático. También habrá excepciones, como veremos.

La siguiente intervención fue de Villanueva, al añadido ya apuntado por Borrull, este diputado introduce una nueva discusión en torno a la palabra reunión.

\footnotetext{
${ }_{1.6}^{15}$ Ibid., p. 1687.

${ }^{1.6} \mathrm{Ibid}$.
} 
Inmediatamente es apoyado por Antonio Capmany, quien considera el término inapropiado para el asunto de que se trata y sugiere la utilización de otras palabras como unión, comunión o conjunto. La discusión se deslizó al terreno metafísico. La facción servil se oponía a la utilización del término reunión porque suponía admitir filosóficamente un pacto social, e ideológicamente las bases de la soberanía nacional. ${ }^{17} \mathrm{Ni}$ más ni menos. Suponía admitir las bases de un Estado contractual, es decir, liberal.

Intervino Argüelles, como casi siempre, categórico:

La comisión no se desentendió de la escrupulosidad con que debía proceder en el lenguaje, y no le costó pocas fatigas; pero sólo puedo decir al señor preopinante que tampoco desconoció que el lenguaje es metafórico, porque es casi imposible una exactitud tan grande, cuando el objeto principal son las ideas. La dificultad de observar esta precisión académica sólo se conoce en el acto de aplicar las palabras a los pensamientos. ${ }^{18}$

Ciertamente fue una difícil tarea la de la comisión redactar las bases de una Constitución liberal, hispana, católica y monárquica, entre otras consideraciones.

Sigamos. Fue Llamas quien introdujo en el debate los conceptos principales del artículo: nación y soberanía. En un discurso estudiado, se atrevió a adentrase en la significación teórica de los conceptos. Consideraba que la nación era la unión del pueblo español con su monarca y que la soberanía sólo podía ser compartida en-

${ }^{17}$ Chust, Cuestionn, 1999 , p. 130.

${ }^{18}$ DSC, 25 de agosto de 1811 , p. 1687. tre ambos. Es más, Llamas, valiente, manifestó en la Cámara que: "La soberania real y verdadera sólo la admito en la nación." Era la apuesta del liberalismo que se movía entre "el gobierno despótico" -la soberanía del rey- y el "democrático" -del pueblo. Entramos en el terreno de la mistificación liberal, pero también en la apuesta decidida del liberalismo por un Estado constitucional, equidistante entre el monarca y el pueblo, entre el absolutismo y la democracia.

Pero restaba más. Intervino José Miguel Guridi y Alcocer, diputado por la provincia novohispana de Tlaxcala. Entre disquisiciones filosóficas, Guridi y Alcocer rompió el consenso liberal que presidía el debate. Ya lo hemos estudiado en otras obras. Lo subrayamos aquí. Entre otras consideraciones, las suyas eran objeciones de amplio contenido. La cuestión nacional hispana se planteó. ¡Y de qué forma! Como ya habían hecho otros diputados anteriormente, se opuso al concepto reunión porque consideraba que sólo expresaba una segunda unión de algo que ya había estado unido y luego se separó. Pero Guridi llegó más lejos. Expresó, ante la sorpresa de los peninsulares y algunos americanos, el desagrado que le causaba la palabra española como definición de la nación: "pues no parece lo más claro y exacto explicar la nación española con los españoles, pudiéndose usar de otra voz que signifique lo mismo". ${ }^{19}$ ¿A qué nación se refería entonces? Si no era a la española, ¿era a la americana?, ¿a la hispana, tal vez?

Es trascendental. Fue trascendental, que en este primer día de discusiones parlamentarias ya se planteara otra denominación de nacionalidad alternativa a la

${ }^{19}$ Ibid., p. 1688. 


\section{SECUENCIA}

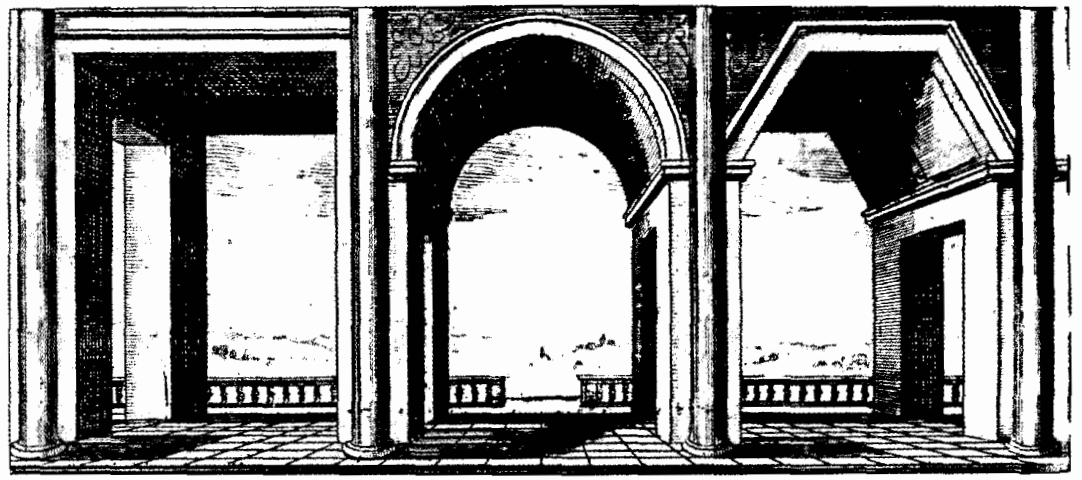


hegemónica hasta ahora: la española. Y fue un americano quien lo planteó. Este diputado conocía perfectamente que la definición de nación, tal y como la presentaba la comisión, suponía la aceptación de una sola nacionalidad, la española, dejando fuera de ella la pluralidad nacional que podían representar los territorios americanos. Es más, a lo largo de los debates, numerosos diputados mistificarán la nomenclatura de nación, refiriéndose tanto al ente cultural como a la formación política. Guridi no jugó con esta ambigüedad:

Tomando, pues, físicamente a la nación española, no es otra cosa que la colección de los nacidos y oriundos de la península, la cual se llama España. Pero aun tomando políticamente la nación española por el Estado, no hallo exacta su definición. ${ }^{20}$

\section{Veamos:}

La unión del Estado consiste en el gobierno o en la sujeción a una autoridad soberana, y no requiere otra unidad. Es compatible con la diversidad de religiones, como se ve en Alemania, Inglaterra y otros países; con la de territorios, como en los nuestros, separados por un océano; con la de idiomas y colores, como entre nosotros mismos, y aun con la de naciones distintas, como lo son los españoles, indios y negros. ¿Por qué, pues, no se ha de expresar en medio de tantas diversidades en lo que consiste nuestra unión, que es en el gobierno? ${ }^{21}$

Un momento. ¿Acaso no estaba reclamando Guridi y Alcocer un espacio en la

${ }^{20}$ Ibid., pp. 1687-1688.

${ }^{21} \mathrm{lbid}$. nación para los indios y las castas? ¿Ya sabía la exclusión de derechos civiles y políticos que la Constitución hacía de ellos en los artículos 22 y 29? Es notorio que sí. Pero su discurso trascendía más allá de cuestiones nacionales, étnicas o raciales. La definición de nación que el diputado novohispano proponía como alternativa fue la siguiente: "la colección de los vecinos de la península y demás territorios de la monarquía unidos en un gobierno, o sujetos a una autoridad soberana". ${ }^{22}$ Definición sutil y lo suficientemente ambigua para no traslucir a primera vista su intención. ¿No estaba planteando una nación hispana que incluyera varias nacionalidades, quizá americanas, junto a la española? Pero lo más importante ¿proponía Guridi también varias soberanías que representaran a estas naciones? ¿No suponía esto la creación de un Estado-nación hispano federado? Atrevida la propuesta del novohispano. Ningún otro americano apoyó a Guridi, al menos públicamente, en este artículo. Otra cosa será cuando se discutan los artículos concernientes a ayuntamientos y diputaciones.

No obstante el precedente era peligroso. Argüielles y Espiga, ¡nada menos!, miembros de la comisión de redacción, replicaron de inmediato al novohispano. Sus discursos contenían voces de alarmas conceptuales. Esta vez "federalismo" no resonó en la Cámara. Quedaba para la discusión de otros artículos constitucionales como los anteriormente mencionados. Argüelles, en primer lugar, lamentaba la divagación de los discursos: "Si los señores preopinantes hubieran expuesto sus opi-

${ }^{22}$ Ibid. 
niones con más claridad, no habría sido necesario explicarse con tanta difusión."

El diputado por Asturias refutará la intervención de Guridi argumentando que no era posible considerar a todos los habitantes de un país como miembros de la nación, porque se estaría considerando españoles a los extranjeros residentes en él. De esta forma tan escueta, Argüelles rehuía entrar en el debate sobre el federalismo que apuntaba el americano. Debate que, como sabemos, se reabrirá posteriormente en la Cámara.

La intervención de Espiga fue magistral. Cansado ya de escuchar la serie de errores en la que continuamente incurrían los diputados, se encargó de poner en orden las ideas y advirtió de forma contundente: "No se debe olvidar, señor, que la nación y el gobierno son cosas muy diferentes y cualquiera que las confunda no puede tener idea de política." 23

Justo cuando parecía que la discusión se iba a tornar interminable, intervino -Francisco Gómez Fernández sorprendiendo a la Cámara con su petición. El diputado por Sevilla inquirió a la comisión de Constitución a que explicara detenidamente, artículo por artículo, a qué antigua ley sustituía y si ésta estaba aún en vigor o no. Lo sorprendente en este caso no es la petición de Gómez Fernández, sino su decisión de "protestar toda la Constitución" si no se proporcionaba esta información. El revuelo que se formó en el oratorio de San Felipe es imaginable. Inmediatamente el presidente de la Cámara tacha de "escandalosas" las declaraciones del diputado sevillano y pide la confianza de todos en los miembros de la comisión.

${ }^{23}$ Ibid., p. 1690.
El problema no cesó. Otros diputados fueron más lejos. Nicolás Martínez Fortún amenazó con renunciar a sus poderes y retirarse a su pueblo si seguía adelante la proposición de Gómez Fernández. Calatrava pidió respeto:

Señor, al oírse la protesta del señor Gómez Fernández no ha podido menos que escandalizarse el Congreso. Es menester poner fin a estas cosas. Continuamente estamos viendo citar aquí las leyes, como si fuera éste un colegio de abogados y no un cuerpo constituyente. $^{24}$

i¿No era la Constitución la reforma de las antiguas leyes?! El historicismo de algunos liberales se desmontó. Estamos en uno de los puntos centrales del debate constitucional. Los liberales, convencidos, apostaron sin reservas por la revolución jurídica.

La calma y el fin de la discusión llegaron con la intervención de Antonio Oliveros, el diputado extremeño y miembro de la comisión, suavizó la cuestión dando su opinión sobre el artículo a debatir:

[...] la nación es la reunión de todos los españoles de ambos hemisferios, las familias particulares que están unidas entre sí, porque jamás hubo hombres en el estado de la naturaleza; y si hubiera alguno, nunca llegaría al ejercicio de su razón: estas familias se unen en sociedad, y por esto se dice reunión. Es una nueva unión y más íntima que antes tenían entre sí; y de los "españoles de ambos hemisferios", para expresar que tan españoles son los de América como los de la península, que "todos componen una sola nación". 25

${ }^{24}$ Ibid., p. 1691.
${ }^{25}$ Ibid. 
Oliveros puso el punto final al debate que inició Guridi. O al menos eso creyó. La fracción liberal peninsular se escoraba hacia el centralismo. Era la presión americana la que lo obligaba. Restaban muchos más artículos y más cuestiones. Por último, el artículo se sometió a votación y quedó aprobado tal y como lo había propuesto la comisión en un primer momento.

Tres días después, el 28 de agosto, se reanudaron las discusiones sobre el proyecto de Constitución. Se leyó el artículo $2^{\circ}$ : "La nación española es libre e independiente, y no es ni puede ser el patrimonio de ninguna familia ni persona." 26

La discusión de este segundo artículo fue breve. La primera intervención fue de Francisco Morrós, quien sólo pidió la inclusión de un pequeño texto a la redacción original: "ni en su todo, ni en ninguna de sus partes". ${ }^{27} \mathrm{~A}$ continuación el discurso de Antonio Llaneras del sector servil. Admitió la última parte del artículo, pero expresó sus reticencias a admitir la primera parte como estaba. Llaneras dio un giro al sentido de las palabras "libre e independiente", pues temía que pudieran entenderse de forma arbitraria. Para él, y lo aclaraba en su discurso, la libertad e independencia se entendían como la voluntad de estar ligados a la religión católica bajo el mando de Fernando VII, en el primer caso, y el no verse subyugados a ningún tipo de dominación extranjera, en el segundo. Señas de identidad de la nación española: religión y monarquía. Leámoslo en el Diario de Sesiones de Cortes:

${ }^{26}$ Ibid., 28 de agosto de 1811, p. 1706.

${ }^{27}$ Ibid.
En el sentido propuesto, digo, señor, y suscribo a lo que dice el capítulo que la nación española es libre e independiente; pero no libre e independiente en otro sentido, esto es que pueda expeler a abandonar la religión santa que profesa, las sabias y justas leyes que la rigen, el suave dominio de Fernando VII y de sus legítimos sucesores: [...] es mi dictamen que se le añada una expresión que declare el sentido verdadero de esta libertad e independencia, y se diga: la nación española es libre e independiente "de toda dominación extranjera". ${ }^{28}$

La intervención de Llaneras apuntaba directamente al artículo tercero que todavía estaba por discutirse, pero que incluía, como veremos, la posibilidad de que la nación eligiera la forma de gobierno más conveniente según su situación. Estaba claro, el sector absolutista veía cómo iba perdiendo poder la figura del rey, primero la soberanía, ahora el patrimonio real. ¡Y todavía estamos en el segundo artículo! $Y$ es evidente que en la redacción de este artículo habían tenido mano los diputados americanos de la comisión, porque, ¿qué gran parte de la nación era patrimonio real? ¿No era América propiedad del monarca por derecho de conquista? Señalemos, insistamos: aquí se definía la nación como entidad territorial y jurídica. Todavía no se había decidido cómo se articularía esa nación de forma territorial, pero el artículo $1^{\circ}$ ya había admitido la igualdad de los españoles de América con los de la península. Ambos formaban parte de una sola nación y, por lo tanto, con este segundo artículo arrebataban al rey gran parte de su poder abso-

$$
{ }^{28} \text { Ibid. }
$$


luto, desligando jurídicamente las antiguas colonias ultramarinas y sus ciudadanos de la soberanía real. Una contradicción más que añadir al ya de por sí difícil reto de conjugar una nación liberal hispana manteniendo sus parámetros monárquicos.

Pero sigamos el breve debate a que dio lugar este artículo. Tras la intervención de Llaneras fue Muñoz Torrero quien tomó la palabra. Con evidentes signos de enfado por las palabras de su predecesor, le recriminó su crítica a las supuestas intenciones de los miembros de la comisión a la hora de redactar el artículo. Espiga salió en su apoyo, y en su estilo duro y contundente, como ya hiciera en el artículo $1^{\circ}$, consideró las palabras de Llaneras de "repetición ridícula, que es más digna de compasión que de impugnación, no debieran merecer la atención de V. M." ${ }^{29}$ Pero el diputado catalán va más allá, visiblemente indignado por estas acusaciones, no puede contenerse por más tiempo y adelanta lo que será el punto más importante y más controvertido del artículo $3^{\circ}$, atribuyéndolo directamente a la verdadera intención de la comisión:

[...] una nación es libre para hacer cuanto convenga para su prosperidad y para su gloria, observando el derecho de gentes a que están obligadas recíprocamente las naciones. Es decir, que una nación mientras que obra según el derecho de gentes, puede hacer lo que más bien le parezca y le convenga para su mayor bien. Vea V. M., y vea también el señor preopinante, las intenciones de la comisión y la verdadera idea de esta palabra libre, y también de la de independiente, que es una consecuencia, y que no es otra cosa que

${ }^{29} \mathrm{Ibid}$. el derecho que toda nación tiene de establecer el gobierno y leyes que más le convengan [...]. ${ }^{30}$

A continuación, y tras la contundencia de Espiga, se procede a la votación del artículo, quedando aprobado tal y como estaba con la única supresión de la palabra $e l$, a petición del señor Villanueva.

\section{¿UNA SOLA SOBERANÍA NACIONAL?}

Sigamos. El artículo $3^{\circ}$ se concebía en estos términos: "La soberanía reside esencialmente en la nacion, y por lo mismo le pertenece exclusivamente el derecho de establecer sus leyes fundamentales, y de adoptar la forma de gobierno que más le convenga." 31

La discusión sobre este artículo se prolongó durante dos días, con él terminaba el capítulo I, destinado a la definición de la nación y de su soberanía. Como en otras ocasiones, fue un diputado absolutista el primero en presentar sus reparos a la redacción del artículo, y curiosamente no fue la primera parte de éste lo que lo llevó a intervenir, sino la sutil y peligrosa última frase del mismo.

Felipe Aner consideraba la frase redundante, dado que ya se expresaba el derecho de la nación a establecer sus propias leyes. No concluyó aquí su intervención. Interpeló a la Cámara para que considerara el sentido democrático de estas palabras, en un claro alegato liberal. El diputado catalán opinaba que la última frase podría ser utilizada por los enemigos de las Cortes para acusarlos de querer estable-

${ }^{30} \mathrm{Ibid}$., 28 de agosto de 1811, p. 1707. Las cursivas son nuestras.

${ }^{31}$ Ibid. 
cer una república con principios democráticos. Y no era para menos, la Francia napoleónica, invasora y enemiga, era un buen ejemplo de ello.

Muchas veces se nos ha acusado de que seguíamos principios enteramente democráticos, que el objeto era establecer una república (como si las Cortes, señor, no hubiesen tomado el pulso a las cosas, y no conociesen la posibilidad de las máximas). No demos, pues, ocasión a que los enemigos interpreten en un sentido opuesto el último periodo del artículo que se discute, y lo presenten como un principio de novedad y como un paso de la democracia. ¡Cuántos habrá que al leer el artículo habrán dicho: "las Cortes no pudiendo prescindir del gobierno monárquico, porque es la voluntad expresa de toda la nación, se reservan en esta cláusula la facultad de hacerlo cuando tengan mejor ocasión!" No es menos atendible, señor, la interpretación que las naciones extranjeras podrán dar a este principio.

Aner introdujo dos cuestiones importantes en su discurso: las limitaciones del monarca por el legislativo y la cuestión internacional.

El siguiente diputado en intervenir fue Vicente Terrero. En un discurso directo, no veía ningún inconveniente en el artículo tal y como se hallaba redactado, tan sólo que después de nombrarse las leyes fundamentales debería incluirse: "y las demás convenientes y necesarias para el buen régimen de gobierno". ${ }^{32} \mathrm{La}$ controvertida última frase no lo era tanto para él, puesto que la consideraba incluida en la adición que había sugerido. Es más, la defendió clara y contundentemente:

$$
{ }^{32} I b i d \text {, p. } 1708 .
$$

Pero no puedo menos de manifestar que no sería fuera de propósito este anuncio o significación; primero, porque es una verdad; ¿y por qué se han de ocultar las verdades? [...] En segundo lugar, porque en nada la contradice que la nación se haya constreñido y ligado con el vínculo de su juramento para conservar su actual y presente Constitución monárquica. [...] Resulta de todo que la cláusula en cuestión ofrece una noción exacta: exacta, porque la nación tiene la facultad y radical poder: exacta, porque ha formado su Constitución libremente: exacta, porque aun cuando por las vicisitudes de los tiempos se vea impulsada a imponer nuevo orden e introducir reformas no sirve de óbice el enunciado juramento. [...] repito que por mí habría de correr como se halla. ${ }^{33}$

Sin embargo, Terrero no dejó pasar la oportunidad para establecer los límites de la monarquía. Los reyes, parafraseando a Mejía, "ya no bajaban del cielo". Terrero puso al monarca también en el suelo, terrenal:

[...] bumani nibil a me alienum puto. Todo cabe en la clase de humano, y en ella no está exento el monarca. Sepan, pues, las cabezas coronadas, que en un fatal extremo, en un evento extraordinario, no fácil, mas sí posible, la nación reunida podría derogarle su derecho. Esto tenía que decir, y dije. ${ }^{34}$

Era la hora de Agustín Arguielles. Grave, hizo una defensa de la redacción que proponía la comisión, de la monarquía: "Yo siempre he visto gobernada a España por la forma monárquica”, y del derecho moral, ético y teológico de la na-

${ }^{33} \mathrm{Ibid}$.

${ }^{34}$ Ibid. 
ción a dotarse de sus leyes fundamentales, es decir, de una preeminencia del legislativo frente al ejecutivo. El modelo de Arguielles, quien lejos de ocultarlo lo explicitó, era Gran Bretaña frente a la revolucionaria Francia:

Su fiel aliada es buen testigo de esta verdad; pues aun en los tiempos más calamitosos de sus revoluciones fue respetada por nosotros y por toda la Europa [...]. solo el trastorno de todas las leyes y de todos los derechos por la revolución de Francia es el que ha introducido el pernicioso ejemplo de respetar poco tan discreta como ventajosa política. ${ }^{35}$

El diputado asturiano, que en otras ocasiones había salido a la tribuna a defender la monarquía frente a las pretensiones autonomistas y federalistas de los americanos, esta vez justificó las limitaciones impuestas al poder del rey. Escuchemos al Divino:

El Congreso oye todos los días la lamentable confusión de principios en que se incurre, que con tal que en España mande el rey, las condiciones o limitaciones se miran como punto totalmente indiferente. [...] Por lo mismo la comisión ha querido prevenir el caso de que si por una trama se intentase destruir la Constitución diciendo que la monarquía era lo que la nación deseaba, y que aquélla consistía solamente en tener un rey, la nación tuviese salvo el derecho de adoptar la forma de gobierno que más le conviniere, sin necesidad de insurrecciones ni revueltas. ${ }^{36}$

\footnotetext{
${ }^{35}$ Ibid., p. 1709.

${ }^{36}$ Ibid., 28 de agosto de 1811, p. 1710.
}

El discurso de Argüelles no estuvo estructurado como en otras ocasiones. Era difícil enunciar el equilibrio liberal, su mistificación monárquica y revolucionaria. Una revolución liberal con un rey constitucional, ayer absoluto. Toda una constante del liberalismo, no sólo español, sino europeo. El extraordinario peso mental, simbólico y de identidad de la monarquía. ¿Demasiada losa para el liberalismo hispano? Quizá en esta primera situación revolucionaria. Desde 1814 la perspectiva será otra muy distinta, al menos para los americanos.

No obstante Argüielles intentó ser concluyente. Se trataba, él y la comisión lo sabían, de uno de los artículos más importantes de la Constitución. El Divino, portavoz de la comisión, terminó: "Lo que constituye para todo hombre sensato la monarquía, o la forma de gobierno monárquico, son las leyes fundamentales que templan la autoridad del rey: lo contrario es una tiranía." 37

Finalizó su discurso pidiendo, casi rogando a las Cortes, que en caso de suprimirse la cláusula se le permitiera a la comisión hacer una adición que pudiera ajustarse al objeto del plan inicial. ¿Qué pasaba? ¿Sabía ya el diputado liberal que la votación estaba perdida? ¿Conocía ya el poco consenso que existía entre el liberalismo hispano en esta cuestión? Difícil y trascendental asunto.

Francisco Javier Borrull, el diputado absolutista por Valencia, alcanzó también la tribuna. Se esperaba una defensa contundente de la monarquía como Estado absolutista. El valenciano rebatió el artículo en todos sus puntos comenzando por la polémica última frase. Argumentó

${ }^{37} \mathrm{Ibid}$. 
que el Estado se hallaba constituido desde hacía muchos siglos y que se eligió, en su momento, la forma monárquica de gobierno con una corona de rasgos sucesores y no electivos. Además, su discurso contenía una crítica a los liberales: la utilización en sus argumentos de autores "filosóficos modernos" para defender sus posturas. Pero aún fue más lejos en su razonamiento al negar el derecho de la nación a establecer sus leyes fundamentales. Derrotado en los dos artículos anteriores, el sector servil no podía permitir más que la Constitución siguiera reduciendo el poder del monarca en detrimento de la nación. Leamos:

Y como sea un principio de derecho que ninguno puede ser despojado de su posesión sin ser citado ni vencido, procede con mayor motivo el que no se pueda quitar al rey estando cautivo la parte que tiene del poder legislativo, ni establecer otra ley que revoque ésta. También ha de contarse entre las fundamentales la de no ser electiva la corona [..] y así no pueden, sin concurso ni consentimiento suyo, quitárseles derechos algunos de los que por ellas se les conceden, ni decirse ahora sin restricción alguna que pertenece exclusivamente a la nación la facultad de establecer las leyes fundamentales. ${ }^{38}$

Puntualicemos. Borrull estaba reclamando algo que ya se había decidido en el primer día de reunión de las Cortes, la división de poderes que dejaba al monarca sin la facultad legislativa ni la judicial. Ya lo hemos estudiado en las primeras páginas de este trabajo. Ahora lo rescatamos. No obstante, los absolutistas no parecían dispuestos a aceptar los cambios jurídicos y políticos, rápidos y consecuentes, que se habían establecido en apenas once meses de parlamentarismo.

Pero además, el diputado absolutista tampoco aceptaba la palabra esencialmente para referirse a la soberanía que residía en la nación. Y es que se resistía a reconocer que el monarca pasara a ser constitucional, cuyo poder se limitaba al ejecutivo controlado por las Cortes. Veamos la confusión en la que incurre Borrull:

$\mathrm{Y}$ debo igualmente manifestar que V. M. ha obligado a todos los diputados a que juren "conservar (son palabras formales del juramento) a nuestro muy amado soberano señor don Fernando VII todos sus dominios", y así, a reconocerle por soberano y a entender esta palabra en sentido propio, por ser ajeno de su voluntad y justificación, como también de la solemnidad del acto contrario. Mas ahora se propone en este artículo que la soberanía reside esencialmente en la nación. Pero si reside esencialmente en la nación, no puede separarse de ella ni el todo ni parte de la misma, y por consiguiente, ni competir parte alguna al señor don Fernando VII; con todo, V. M. ha mandado reconocerle por soberano; luego según la declaración de V. M. tiene parte de la soberanía; luego ha podido separarse, y por lo mismo no puede decirse que reside esencialmente en la nación, y así no hallo arbitrio para aprobar el referido artículo $3^{\circ}$ en los términos en que está concebido. ${ }^{39}$

Más contundente aun que Borrull fue el obispo de Calahorra, que entregó su discurso al secretario para que lo leyera. Este diputado, bajo ningún concepto, aceptaba el artículo $3^{\circ}$, es más, pedía que

${ }^{39} \mathrm{Ibid}$., p. 1712. 
se borrara de la Constitución así como también todos aquellos que declararan que la soberanía recaía en la nación. El obispo: "Señor, a Fernando VII corresponde ser monarca soberano de las Españas; el sólo imaginar la menor novedad en este punto esencial de nuestra Constitución, me hace estremecer." 40

La contradicción que suponía construir un Estado nacional con parámetros hispanos y transoceánicos manteniendo la monarquía como forma de gobierno era más de lo que el sector servil podía transigir. El obispo de Calahorra insistió en que la soberanía la tenía el rey derivada directamente de Dios y, por lo tanto, nadie podía despojarlo de esta suprema potestad.

No fue el discurso del obispo el último de los absolutistas. La resistencia contra la soberanía nacional fue tenaz. Intervino José Ramón Becerra y Llamas, su definición de nación es todo un ejemplo de sus propuestas monárquicas: "la nación española es aquel cuerpo moral que forman el pueblo español y el soberano español como su cabeza, y que constituyen lo que llamamos monarquía española". ${ }^{41}$ ¿Pero no había sido aceptado ya el artículo $1^{\circ}$ ? ¿A qué venía ahora definir a la nación, incluyendo al rey en ella? Además, esta definición admitía una soberanía compartida entre el pueblo y el monarca, todo lo contrario a lo planteado por la comisión.

El contrapunto lo puso, otra vez, el novohispano Guridi y Alcocer. Recordemos que ya había intervenido en el artículo $1^{\circ}$ desmarcándose del consenso liberal hispano. En esta ocasión pretendía

$$
\begin{aligned}
& { }^{40} \text { Ibid. } \\
& { }^{41} \text { Ibid. }
\end{aligned}
$$

sustituir la palabra esencialmente por la voz radicalmente, ${ }^{42} \mathrm{o}$ bien originariamente, para expresar con más claridad la fuente de donde emanaba la soberanía. Guridi y Alcocer:

De lo que no puede desprenderse jamás es de la raíz u origen de la soberanía. Ésta resulta de la sumisión que cada uno hace de su propia voluntad y fuerzas a una autoridad a que se sujeta, ora sea por un pacto social, ora a imitación de la potestad paterna, ora en fuęrza de la necesidad de la defensa y comodidad de la vida habitando en sociedad; la soberanía, pues, conforme a estos principios de derecho público, reside en aquella autoridad a que todos se sujetan, y su origen y su raíz es la voluntad de cada uno. ${ }^{43}$

El contrapunto lo puso Guridi y Alcocer, el punto y aparte, Muñoz Torrero. Molesto, irritado, fue concluyente y breve:

${ }^{42}$ Guridi y Alcocer realizó la misma propuesta en la discusión del artículo $3^{\circ}$ del Acta de la Federación Mexicana en donde se proclamaba de una forma rotunda la soberanía nacional: "Ia soberanía reside radical y esencialmente en la nación, y por lo mismo pertenece exclusivamente a ésta el derecho de adoptar y establecer por medio de sus representantes la forma de gobierno y demás leyes fundamentales que le parezca más conveniente para su conservación y mayor prosperidad, modificándolas o variándolas, según crea más convenientes." Esta vez, trece años después, su propuesta triunfó. Los resquemores del diputado por Tlaxcala hacia el monarca en 1811 se confirmaron en 1814. Guridi y Alcocer "dijo que desde que fue individuo de la comisión de constitución en las Cortes de España propuso que se dijese que la soberanía reside radicalmente en la nación, para explicar no sólo que la soberanía es inajenable e imprescriptible, sino el modo con que se halla en la nación, pues que ésta conserva la raíz de la soberanía, sin tener su ejercicio".

${ }^{43}$ DSC, 28 de agosto de 1811 , p. 1714. 
Como individuo de la comisión pido a V. $M$. que no permita que se ponga el decreto de 24 de septiembre [...] Los discursos que acabo de oír se dirigen a otra cosa que a impugnar la soberania de la nación. ${ }^{44}$

El debate estaba en un punto de tensión. Intervino también el conde de Toreno. Convenía zanjar la cuestión, rebatir argumentos. Pormenorizadamente explicó a cada uno de sus predecesores los errores en los que habían incưrrido. Todos los absolutistas y el americano fueron nombrados; sus argumentos rebatidos. Toreno insistía en la confusión de términos en la que incurrían, a su parecer, continuamente estos diputados: Cortes con nación, soberanía con gobierno. Al mismo tiempo recordaba a la Cámara, con contundencia, algunos conceptos. Escuchemos sus palabras:

¿Qué es la nación? La reunión de todos los españoles de ambos hemisferios; y estos hombres llamados españoles, ¿para qué están reunidos en sociedad? Están reunidos como todos los hombres en las demás sociedades para su conservación y felicidades. ¿Y cómo vivirán seguros y felices? Siendo dueños de su voluntad, conservando siempre el derecho de establecer lo que juzguen útil y conveniente al procomunal. ¿Y pueden, por ventura, ceder o enajenar este derecho? No; [...] la soberanía reside en la nación que no se puede partir, que es el super omnia al cual no puede resistirse [...]

Radicalmente $u$ originariamente quiere decir que en su raíz, en su origen, tiene la nación este derecho, pero no que es un derecho inherente a ella; y esencialmente expresa que este derecho coexiste, ha coexis-

${ }^{44}$ lbid. tido y coexistirá siempre con la nación mientras no sea destruida; [...] así jamás delega el derecho, y sólo sí el ejercicio de la soberanía. $^{45}$

Bastante claro el discurso de Toreno, quien de forma contundente instó a la Cámara a defender la Constitución para conservar la libertad de la nación o a someterse a los decretos de Bayona y al enemigo francés. No era esto, precisamente, lo que se estaba debatiendo. Ia pugna en este momento era diáfana: rey absoluto-monarquía constitucional. Como en otras cuestiones, Toreno desvió el tema central.

El día 29 se reanudó la discusión del artículo $3^{\circ}$. Tomó la palabra Juan Nicasio Gallego. Los ánimos estaban caldeados, no olvidemos el contexto. El estruendo de los cañonazos franceses podía oírse desde el oratorio de la iglesia de San Felipe Neri. Gallego no sorprende a la Cámara. Inicia un encendido discurso en defensa de la soberanía nacional y del establecimiento de las propias leyes y forma de gobierno.

Después de la solemne declaración que las Cortes hicieron el 24 de septiembre de que residía en ellas la soberanía de la nación española, es doloroso verse en la necesidad de probar que esta nación es soberana, y que esencialmente le compete esta calidad. ${ }^{46}$

De repente es interrumpido por un diputado, Antonio Alcaina, que le manifiesta "que ya no se podía seguir adelante". El presidente lo llama al orden. Gallego, imperturbable, le pide explica-

is Ibid., p. 1715.

${ }^{46} \mathrm{Ibid}$. 
ciones sobre su manifestación. Algunos diputados claman para que continúe su discurso. La situación es tensa, absolutistas y liberales se rebaten unos a otros los argumentos en pro y en contra del artículo. El decreto del 24 de septiembre de 1810 se ha leído ya tres veces en la Cámara. La pugna entre ambas facciones es tenaz. El contenido del artículo lo merece.

En ese momento, Francisco Fernández Golfin pronuncia las palabras más contundentes que se han oído en la planta elíptica:

Yo reclamo estos principios [principios constitutivos de la sociedad] que deben dirigir nuestras deliberaciones. Si es necesario desenvolverlos yo lo haré sin temor de que me llamen jacobino, y demostraré que el que no los sostiene perjudica a la nación y destruye los derechos de nuestro legítimo rey Fernando VII. ${ }^{47}$

Contraataca ahora la facción servil. Villagómez, Lera, después Inguanzo. El segundo opina que la nación ya constituida ha decidido sus leyes y su forma de gobierno, que es la monarquía y, por lo tanto, le parece innecesario el resto del artículo. Lo que llama la atención es que sigue a Guridi y Alcocer en el uso del concepto radical. ¿Intenta atraerse a los americanos? Por cierto, ¿dónde están en el debate de este tercer artículo?

Pedro Inguanzo sube a la tribuna y su primera opinión es que el artículo no debe entrar a formar parte de la Constitución. Escandalizado ante las pretensiones de la comisión, se pregunta por qué han de ser los españoles los primeros en sancionar semejantes axiomas políticos hasta enton-

${ }^{47}$ Ibid., p. 1721 . Las cursivas son nuestras. ces no fijados en ninguna Constitución. Ejemplifica que este tipo de actuaciones sólo puede acarrear males a la sociedad, como en el caso de la revolución francesa, y considera que el pueblo es demasiado dócil e ignorante para residir en él semejante potestad. Escuchémoslo:

¿quién es el pueblo de una nación? El pueblo o la nación española, ya lo ha definido V. M., es la reunión de todos los españoles de ambos hemisferios; lo que constituye pues la voz del pueblo es la universalidad, la mayoria del número. Ahora bien: ¿el mayor número del pueblo dónde está? En los campos, en las aldeas, en los talleres, etc. Los labradores, los artesanos, los menestrales, las mujeres, rústicos, ignorantes, éstos son los que componen el número incomparablemente mayor de una nacion. [...]

Que lo digan si no las revoluciones acaecidas en las demás naciones, las cuales llevando por delante esta soberanía y derechos del pueblo, y socolor de protejerlo y reformar abusos, no han servido más que para levantar sobre él algunos tiranos, que lo han oprimido y desolado la patria, convirtiéndola en un campo de sangre, de escombros $\mathrm{y}$ de ruinas. ${ }^{48}$

Este diputado consideraba que el artículo debatido dotaba a la nación de unas facultades que no le pertenecían y estaba seguro de que nunca se hallaría en la tesitura de tener que ejercerlas.

El tiempo se agota y el liberalismo hispano quema su último cartucho con la intervención de Muñoz Torrero, el encargado de convencer a las Cortes de la necesidad de mantener el artículo $3^{\circ}$ tal y como lo propuso la comisión. El diputado

${ }^{48}$ Ibid., p. 1723. 
extremeño insiste en que la voluntad nacional de negar las abdicaciones de Bayona es un ejemplo de que la soberanía reside en la nación y que como tal, $\mathrm{Na}$ poleón no pudo ni puede usurpársela a Fernando VII, puesto que a éste no le pertenece. En última instancia, advierte que "no es lícito a un diputado votar contra la voluntad nacional". 49

Tras la intervención de Muñoz Torrero se procede a la votación nominal del artículo $3^{\circ}$. Para ello se divide en dos partes, la primera fue aprobada por 128 votos contra 24. Antes de proceder a la votación de la segunda parte, $y$ de adoptar la forma de gobierno que más le convenga, intervino astutamente Felipe Aner. Manifestó que la pregunta no debía ser si se aprobaba o no, "porque conteniendo esta parte una verdad eterna, consecuencia de la primera, no podía reprobarse sin una manifiesta contradicción", por lo cual sólo se consultaba si convenía su supresión "por estar comprendida en la parte aprobada, debía reducirse a esto sólo la pregunta". La Cámara accedió a este razonamiento. La suerte estaba echada con esta propuesta. Insistamos, lo que se votó no fue su supresión, sino si estaba contenida esta expresión dentro de las calidades de la soberanía nacional. Era muy diferente. El resultado fue de 87 votos a favor contra 63. La polémica intencionalidad de una fracción de los liberales y de la comisión finalmente no se incluyó, lo cual no quiere decir que el debate no se produjera, que la pugna entre absolutistas y liberales no se diera y que esta tensión no condicionara otros artículos también importantes, como lo sería el número 12.

${ }^{49}$ Ibid., p. 1725.

\section{CONCLUSIÓN}

En las Cortes de Cádiz se reveló una singular y doble problemática nacional que va a incidir directamente en la cuestión de la soberanía y de la representación. Así se estaba transformando jurídicamente el Estado, ${ }^{50}$ desde el monárquico y absolutista al también monárquico pero nacional y constitucional. Aconteció que este Estado nacional que se estaba fraguando en las Cortes de Cádiz incluyó a los territorios y a los súbditos de toda la monarquía española en calidad de igualdad de derechos y de libertades, convirtiéndolos, respectivamente, en provincias y en ciudadanos.

Aunque los derechos de los ciudadanos americanos y sus fundamentos los explicamos más detenidamente en otros estudios, ${ }^{51}$ lo importante es insistir en que esta cuestión, además de su sesgo revolucionario burgués, comportó una discusión en la Cámara sobre el contenido de la nación y, por ende, de la nacionalidad. Así, iniciada la revolución, ésta implicó no sólo una lucha entre la soberanía del rey frente a la ahora soberanía nacional en construcción, sino también una problemática interna sobre el carácter y la nacionalidad triunfante de esa nación y sobre la división o la unicidad de los mecanismos electorales que componían la representación de la nacionalidad y soberanía $y$, por lo tanto, de su legitimidad.

Así, los conceptos nación, soberanía y representación quedaban ligados en el entramado legitimador que el nuevo Estado

\footnotetext{
${ }^{50}$ Entre la abundante bibliografía sobre el Estado puede consultarse la obra clásica de Zippelius, Teoría, 1998.

${ }^{51}$ Chust, Cuestión, 1999.
} 
liberal no sólo construía, sino que necesitaba enunciar, difundir y, sobre todo, legitimar. En especial porque la legitimidad del Estado, el anterior y el nuevo, recaía absolutamente en el primero y se compartía en el segundo, pero ambos en el monarca.

Se trataba para el liberalismo peninsular y americano de un drama, cambiar el Estado sin modificar su forma de legitimidad -la monarquía- y hacer compatible hasta el antagonismo más frontal, al menos inicialmente, monarquía y Constitución. El cambio era cualitativo en el contenido de Estado, pero no en el de su forma. Es decir, pasar del absolutismo al liberalismo, de la colonia a la autonomía dentro de un Estado-nación e, incluso, realizar la revolución liberal con el mismo rey, Fernando VII, "el deseado" al menos en 1808, el "ausente" hasta 1813, el golpista de 1814, el constitucional obligado de 1820 y el conspirador de 1823. Pero, observemos, nunca el autonomista americano.

Parecía una tarea contradictoria, difícil y problemática la de estos liberales, tanto americanos como peninsulares. $\mathrm{Y}$ lo fue por las comprensibles resistencias de Fernando VII a lo que representaba un Estado liberal, de la clase nobiliaria, tanto laica como eclesiástica, de sus intelectuales orgánicos y de parte de las capas populares alienadas con el paternalismo absolutista.

Monarquía y clase nobiliaria que se negaban a verse superadas por un Estado liberal que atentaba contra sus privilegiados intereses, tanto por la problemática que suponía la revolución en la península como por la pérdida que podía e iba a suponer América para la monarquía como patrimonio real y rentas. De esta forma la problemática americana para la monar- quía, que también se desarrolló desde 1808, no sólo estaba representada por los movimientos insurgentes, sino también por la aplicación de los decretos y de la Constitución gaditana, que van a plantear toda una nueva reformulación del Estado, desde la igualdad de libertades hasta la de representación, pasando por la política y la económica.

\section{HEMEROGRAFía}

Diario de Sesiones de Cortes, 1810-1814.

\section{BIBLIOGRAFÍA}

-Barragán, José, Temas de liberalismo gaditano, UNAM, México, 1978.

-Chust, Manuel, "Revolución y autonomismo hispano: José Mejía Lequerica” en Manuel Chust (ed.), Revoluciones y revolucionarios en el mundo bispano, Universitat Jaume I, Castellón, 2000, pp. 43-62.

- La cuestion nacional americana en las Cortes de Cádiz, IIH-UnAm/Centro Francisco Tomás y Valiente/Fundación Instituto Historia Social, México y Valencia, 1999.

-Portillo Valdés, José María, Revolución de nación. Origenes de la cultura constitucional en España, 1780-1812, Centro de Estudios Políticos y Constitucionales, Madrid, 2000.

-Stoetzer, O. C., El pensamiento político en la América española durante el periodo de la emancipación (1789-1825), Instituto de Estudios Políticos, Madrid, 1966.

- Varela Suances Carpegna, José, La teoría del Estado en los orígenes del constitucionalismo bispánico (las Cortes de Cádiz), Centro de Estudios Políticos y Constitucionales, Madrid, 1983.

-Zippelius, Reinhold, Teoría general del Estado, Porrúa/UnaM, México, 1998. 